\title{
Measuring Compressive Strength Characteristics of Soil-Dobak-Glue Mixtures over Curing Time
}

\author{
Myeonghwan Kim $\mathbb{1 D}^{1}$ and Seongjun Eom $\mathbb{D}^{2}$ \\ ${ }^{1}$ Department of Agricultural and Rural Engineering, College of Agriculture, Life \& Environment Sciences, \\ Chungbuk National University, Chungbuk 28644, Republic of Korea \\ ${ }^{2}$ Agricultural Environment \& Resources Division, National Institute of Agricultural Sciences, Jeollabuk-do, \\ 55365, Republic of Korea \\ Correspondence should be addressed to Seongjun Eom; nice2002@cbnu.ac.kr
}

Received 19 October 2021; Revised 21 December 2021; Accepted 22 December 2021; Published 12 January 2022

Academic Editor: Gladis Camarini

Copyright ( $\odot 2022$ Myeonghwan Kim and Seongjun Eom. This is an open access article distributed under the Creative Commons Attribution License, which permits unrestricted use, distribution, and reproduction in any medium, provided the original work is properly cited.

\begin{abstract}
The building materials used by mankind in the past, such as stone, soil, and wood, have been environment-friendly. However, the various building materials invented over time with the development of the industrial age pose problems such as environmental hormone generation and waste generation/disposal. To overcome these problems, building materials based on soil, a traditional building material, are being developed by researchers. However, the improvement in soil's structural characteristics is insufficient as it excessively emphasizes efficacy and function only. In this study, lime and Dobak-glue were mixed with soil to solve the structural problems and improve the strength of soil, and water content and change in strength in accordance with curing time were tested. In order to understand the change in strength, a compaction test was performed by preparing a standard specimen based on the optimum water content and maximum dry density. The lime mix required optimum water content and quantity of lime equal to $3 \%$ of soil weight, while the Dobak-glue mix was prepared by soil mixing in the same weight ratio as optimum water content. Changes in water content and compressive strength were measured over curing time of 3, 7, and 28 days. Three specimens, lime mixed specimen, Dobak-glue mixed specimen, and standard specimen, were prepared, and their water content and compressive strength values were averaged. Although the change in water content according to the curing period differed depending on the material mixed with soil, there was no significant difference between $7.12 \%$ and $2.82 \%$ after 7 days. As for the change in compressive strength, the initial compressive strength in lime mixed specimen was excellent, but the Dobak-glue mixed specimen displayed the greatest strength after 7 days. To conclude, Dobak-glue is an eco-friendly material, and it can be very useful in compensating for the structural shortcomings of soil.
\end{abstract}

\section{Introduction}

With the emergence of Lifestyles of Health and Sustainability, namely, the pursuit of eco-friendly values to improve the quality of life by enhancing income and awareness, recent years have seen an increased understanding of and demand for sustainable solutions [1]. Owing to the sharply increased use of chemical materials to enhance the usability of modern building materials, the indoor spaces of buildings finished with chemical materials pose serious risks such as sick building syndrome [2]. To solve this problem, more eco-friendly materials are currently being used in architecture and other fields.
Natural materials are eco-friendly and highly sustainable. Their low energy cost and recyclability promise low environmental burden, thus making them ideal for the construction industry [3]. Using natural materials in construction has been encouraged recently, especially in countries where they could be easily accessible and economically attractive resources [4].

Soil is the main environmentally and culturally significant construction material that is widely used in the world. Admittedly, natural constructions have been ignored despite their many advantages, not only in Korea but also worldwide, while modernist architecture, owing to its mass 
producibility and functionality, has become the new norm. Many architects across different regions and cultures have been searching for design methods that can integrate natural materials into various engineering systems and techniques developed in modern times. New possibilities are currently being explored owing to the recently emerging need for ecofriendly construction [5].

The construction industry will keep growing at a fast pace [6]. For instance, China will need 40 billion square metres of combined residential and commercial floor space over the next 20 years-equivalent to adding New York City every two years or the area of Switzerland [7]. Environmentally, this industry accounts for $30 \%$ of carbon dioxide emissions; in addition, the global construction industry consumes more raw materials ( $3000 \mathrm{Mt} /$ year, almost $50 \%$ by weight) than any other economic activity, indicating its unsustainability. The foreseeable increase in the world population (by 2030, it is expected to increase by more than two billion people) and the needs in terms of buildings and other infrastructure will further increase the consumption of nonrenewable materials as well as waste production [6].

To reduce the environmental pollution due to the cement production process, researchers have been investigating sustainable alternatives. Consequently, extensive studies have been ongoing to use viable, economical, and ecofriendly building materials [8].

Soil offers many advantages: it is abundant in nature and is inexpensive. It also generates little waste and contributes to the growth of plants and animals [9]. Recently, many materials that can be used as binders instead of cement have appeared. Among them, materials that are being actively studied include silica fume, blast furnace slag, and fly ash [10]. Dobak-glue is used as a consolidating agent; discoloration on account of degradation is minimal; most of the Dobak-glue samples exhibited a less color change than animal-glue samples; and after moisture absorption and drying, the $0.5 \%$ and $3 \%$ Dobak samples displayed a lower degree of change in the value of color difference [11]. Furthermore, stable results were confirmed when Dobakglue was used in preservation treatment for damaged areas compared to other organic media [12], and Dobak-glue natural adhesives have been known to improve physical and mechanical properties of wall by additives in the earth wall material [13]. Previous research carried out by Kim et al. [12] had resulted in the small change of compressive strength after volume-change-ratio, freezing-thawing, and artificialweathering test.

Thus, it is highly promising for the eco-efficiency of the construction industry and sustainable development [6]. The use of soil, such as red clay, is gaining popularity owing to its affordability and abundance. However, there is still room for improvement in the use of soil with respect to durability and peptization [14]. Soil can be mixed with various additives to improve its durability and enhance water resistance. However, the earth block using soil as the main material was superior in terms of being eco-friendly, but its strength and durability were low, in addition to cracking due to drying shrinkage. To overcome such shortcomings, the development of solidification materials with high performance is required [15]. Therefore, in this study, lime and seaweed gambling grass were mixed in order to compensate for these problems for securing durability and long-term strength that appear as weak elements in soil construction. Changes in water content and strength were observed according to the curing period for each material mixed with soil.

\section{Materials and Methods}

\subsection{Materials}

2.1.1. Dobak. Dobak (Pachymeniopsis elliptica $[16,17])$, glue weed (Gloiopeltis furcata), and jelly moss (Chondrus ocellatus) are seaweed species that are traditionally used to fabricate seaweed-based glue [18]. In Korea, Dobak, an algal species of the genus Grateloupia, has been primarily used to produce glue. The main component of dried Dobak is sugar (polysaccharide), and Dobak-glue is produced from dried Dobak by boiling it in water and filtering out the gluey extract. Traditionally, Dobak-glue has been used to paste paper or bond soil and slaked lime [13].

The use of Dobak-glue as an organic material is hardly documented; instead, its use has been handed down across generations through word of mouth. In Japan, there is a traditional technique that uses other seaweed species, such as jelly moss, for wall application [19]. In Korea, Dobak was more likely used instead because it could be easily obtained by the general public.

Dobak-glue has recently been used for wall reinforcement and restoration. For example, in 2008, it was used for the preservation of the murals of Daeungjeon (main hall) in Heungguksa Temple in Yeosu, Jeollanam-do. Subsequently, it was used in 2010 for the murals of Bogwangmyeongjeon in Wibongsa Temple in Wanju, Jeollabuk-do, and in 2011 for the murals of Uhwaru in Hwaeomsa Temple in Wanju, Jeollabuk-do. Dobak-glue was mostly used in concentrations of $1 \%-3 \%$ [18].

2.1.2. Slaked Lime. The use of slaked lime in improving the strength characteristics of soil (e.g., for canal lining and as a filler for pavements and other engineering structures) has played a very important role in the geotechnical engineering sector [20].

Pure lime is an oxide of calcium carbonate. Lime is divided into quicklime and slaked lime. For construction, lime is used in both forms. In the past, limestone was also used as an aggregate for cement concrete; however, it has since then been replaced by Portland cement. However, with the depletion in natural reserves due to the increased demand for aggregates, different types of aggregates are now being used, including crushed aggregates, and research in underway to explore methods to use limestone as a raw material for aggregates [21].

Lime is used to increase the bonding strength of soil and to improve durability in some soil-based construction methods, such as rammed earth and earth brick methods. Quicklime is used to dry wet soil and increase its strength in rammed earth structures via the exothermic reaction that occurs when it is mixed with water [14]. 
2.1.3. Soil. Red clay soils were collected from the grounds near farm settlements in Yeonjeong-ri, Gangnae-myeon, Heungdeok-gu, Cheongju, and Chungcheongbuk-do. The physical and mechanical properties of the collected soils were tested (see Table 1). Soil testing was conducted in accordance with the KS F standards. Figure 1 shows the grain size distribution and compaction curves.

The physical property test results identified the collected soils as low-compressibility (CL) soils as per the Unified Soil Classification System (USCS) with specific gravity of 2.79 by sampled region and \#200 sieve passage percentage of $52.6 \%$. Compaction experiments revealed that the maximum dry density was $18.14 \mathrm{kN} / \mathrm{m}^{3}$ and optimum water content (OMC) was $13.34 \%$.

\subsection{Experimental Procedure}

2.2.1. Organic Material (Dobak-Glue). In Traditional Science and Technology Research (IV) [13], Dobak-glue is described as having properties similar to those of the sunset hibiscus (Hibiscus manihot), which is used for manufacturing Korean paper, with a $\mathrm{pH}$ range of 6.67-7.26. Dobak is abundant along the east coast of the Korean peninsula and is easy to store compared with sunset hibiscus, which is important because its adhesive power is better when the glue is produced around a year after harvesting.

In this study, $100 \mathrm{~g}$ of dried Dobak was mixed with 2000 $\mathrm{g}$ of water in 1:20 ration and then heated for $1 \mathrm{~h}$. Lee at al. [22] studied the effect of the extraction temperature on the production of kelp (Saccharina japonica) extract, which is similar to Dobak, and reported that the higher the heating temperature, the higher the concentration; however, after 1 hour of heating, no significant difference was observed. The dried Dobak and Dobak-glue used in this study are the same as that in Figure 2.

2.2.2. Soil Sample Fabrication. We prepared three different cylindrical (diameter: $5.0 \mathrm{~cm}$, height: $10.0 \mathrm{~cm}$ ) test samples with a maximum dry density of $90 \%$. The prepared test samples were air-dried for varying curing times of $0,3,7$, and 28 days. The changes in compressive strength were measured for three specimens of each sample type. The measurement equipment can measure a force of up to $5.0 \mathrm{kN}$ and perform speed control in the range of $0.01-30.0 \mathrm{~mm}$.

The prepared test samples were as follows: (1) soil with OMC (SO), (2) soil mixed with 3\% (soil weight ratio) slaked lime (SL), and (3) soil mixed with Dobak-glue in the same weight ratio as the OMC (SS). Each type of test sample was subjected to shrinkage limit and uniaxial compression tests to check crack formation and to measure the soil shrinkage ratio and compressive strength. For specimen preparation, the sample was weighed in three equal parts, and the mould shown in Figure 3 was used. Compressive strength measurements were performed at a displacement control speed of $1.0 \mathrm{~mm} / \mathrm{min}$. Table 2 shows the soil mixture compositions (mixing ratios and additives) of the three samples.

\section{Results and Discussion}

3.1. Shrinkage Limit Measurement Results. The tensile strength of the soil is one of the major strength parameters as it is particularly important to natural or artificial structures containing fine-grained soil, which is sensitive to environmental factors [23]. When constructing a wall, the volume decreases owing to moisture evaporation from the micropores after compaction and curing. Gaps may occur by this decrease in volume, and the stress caused by dry shrinkage may lead to cracks on the wall over time after the mould is removed.

To measure the shrinkage-induced deformation, we performed a shrinkage limit test according to the method specified in KS F 2305 [24]. The shrinkage limit test is a test to find the water content in a state that changes from semisolid to solid. The water content of the samples was set to the liquid limit. Table 3 presents the test results, and Figures 4 and 5 show the states of the samples after $24 \mathrm{~h}$ drying.

The photographs of the three types of samples (SO, SL, and SS) when put in porcelain dishes in the liquid limit state (prior to those in Figure 4) exhibit different surface water content states. In the SS sample, unlike in the SO and SL samples, air bubbles did not escape through the surface even after heating in the porcelain dish. The shrinkage limit after drying for $24 \mathrm{~h}$ in the drying oven was measured to be $16.38 \%$ for SO, $17.34 \%$ for SL, and $23.23 \%$ for SS. No cracks occurred in SO and SL, whereas cracks were observed in SS (following the condition shown in Figure 4). Furthermore, despite the appearance of surface cracks and volume expansion by visual assessment, the volume measurement results showed that the volume was reduced from 21.5 to $19.5 \mathrm{ml}$.

In the OMC test on the three types of samples, no volume change or surface cracking was observed in any of the three samples. It was observed that in SO and SL, the soil in the lower part was broken to a considerable extent, whereas in SS, it was intact (Figure 5).

Soil mixing under the optimum water content condition of soil rather than the corresponding high water content of the liquid limit is advantageous for volume change, but it was found that it is insufficient in SO and SL conditions to increase the bonding strength between soil particles. However, under the SS condition, the volume change, cracking, and soil particle bonding were also good under the optimum water content condition. Lee et al. [25] found that, in the SEM analysis of soil particles in a sample mixed with Dobak-glue, a translucent film was coated on the particle surface or a gel was formed in the void.

\subsection{Curing-Time-Dependent Changes in Water Content.} The three types of samples were air-dried in a room (temperature: $20 \pm 3{ }^{\circ} \mathrm{C}$, relative humidity: $30 \pm 5 \%$ ) and not exposed to direct sunlight.

Figure 6 showed the change in water content with time for each group. A decrease in water content associated with the curing-time-dependent weight change was observed in 
TABLE 1: Physical and mechanical properties of soil.

\begin{tabular}{lcccccccccc}
\hline \multirow{2}{*}{ No. } & \multirow{2}{*}{ Gs } & LL $(\%)$ & PI $(\%)$ & \multirow{2}{*}{$\gamma_{\mathrm{d}}\left(\mathrm{kN} / \mathrm{m}^{3}\right)$} & OMC & \multicolumn{4}{c}{ Grain size distribution (\%) } \\
\hline Soil & 2.79 & 31.4 & 12.5 & 18.14 & 13.35 & 98.9 & 70.1 & 52.6 & 17.5 & CL \\
\hline
\end{tabular}

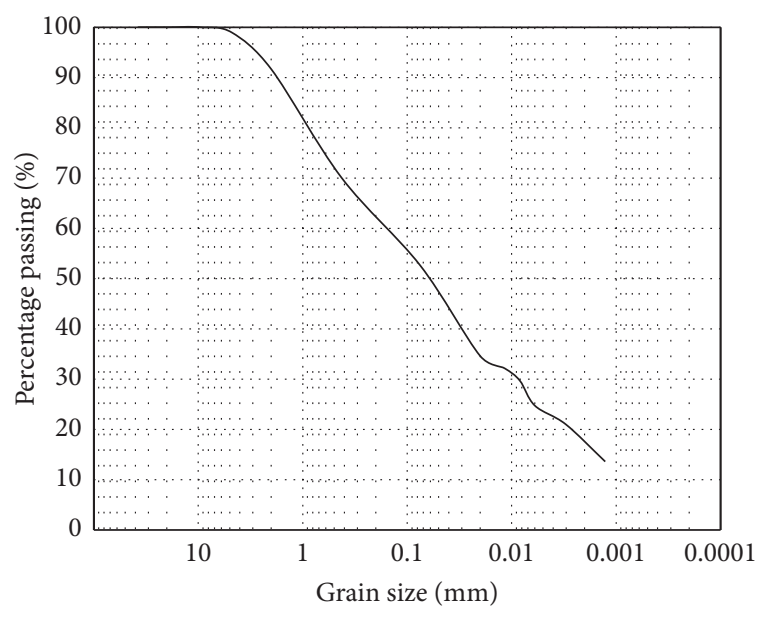

(a)

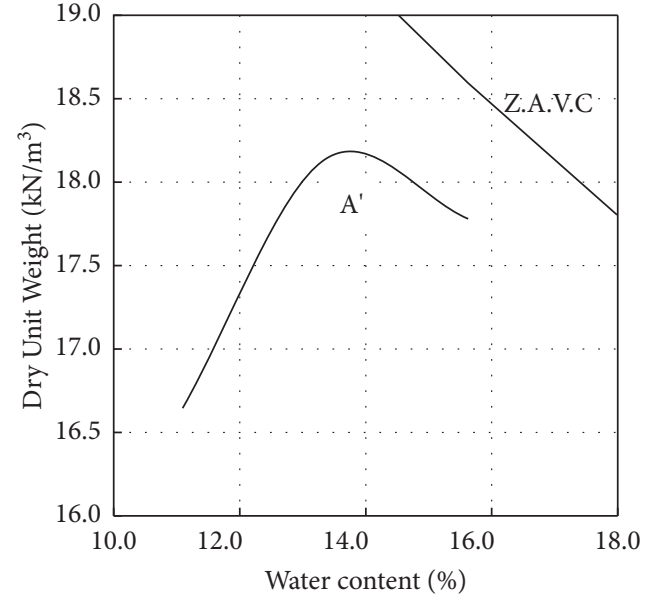

(b)

FIgURE 1: Mechanical properties of soil. (a) Grain size distribution curve. (b) Compaction curve.
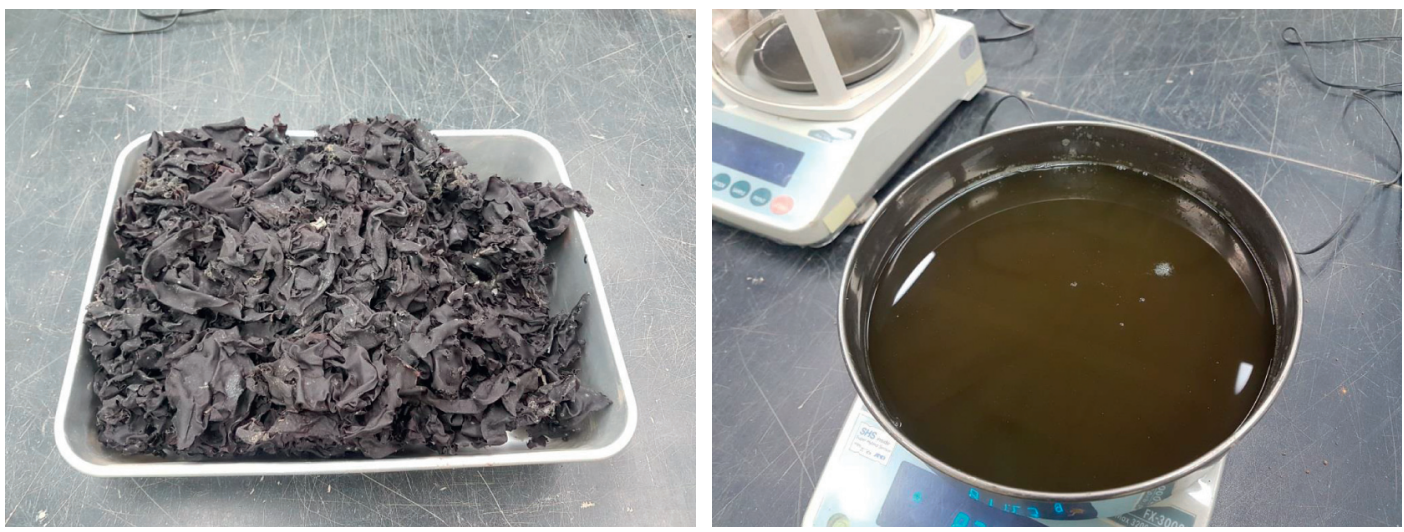

FIgURE 2: Schemes follow the same formatting.

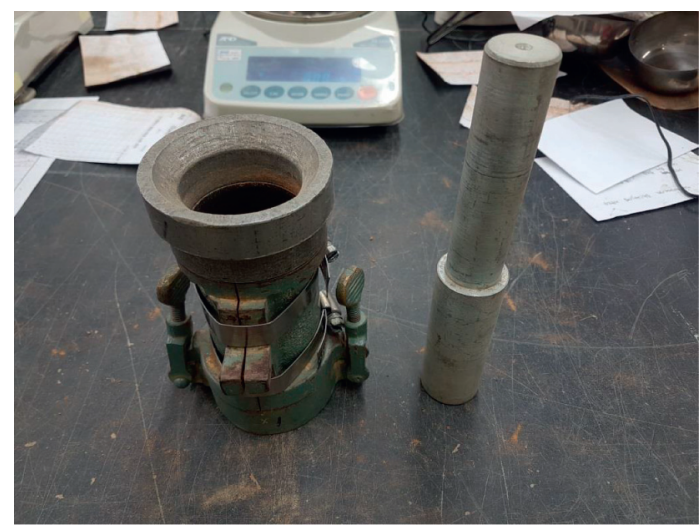

(a)

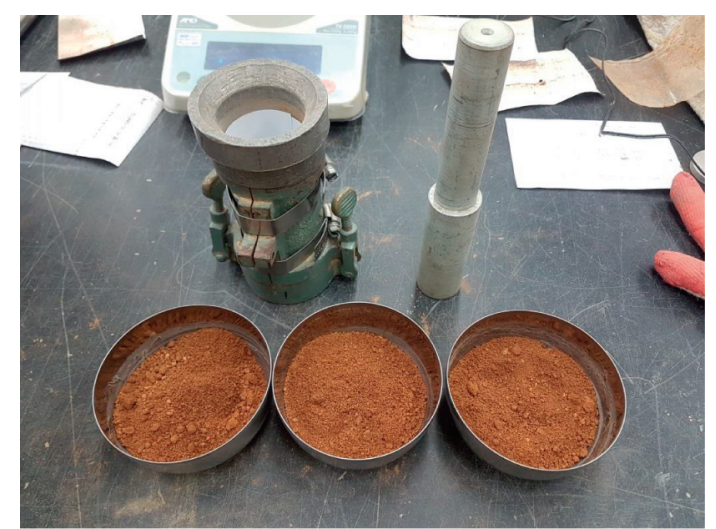

(b)

Figure 3: (a) Specimen mould. (b) Measured soil samples. 
TABLE 2: Composition of soil mixtures.

\begin{tabular}{lcccc}
\hline Sample & Soil & Water & Slaked lime & Dobak-glue \\
\hline SO & & 43.64 & - & - \\
SL & 326.88 & 44.95 & 9.81 & - \\
SS & & - & - & 43.64 \\
\hline
\end{tabular}

TABLE 3: Results of shrinkage limit tests on three types of soil samples.

\begin{tabular}{lccr}
\hline Condition & SO & SL & SS \\
\hline Liquid water content (\%) & 30.24 & 30.73 & 30.29 \\
OMC (\%) & 14.87 & 14.90 & 18.86 \\
Shrinkage limit (\%) & 16.38 & 17.34 & 23.23 \\
Shrinkage ratio & 1.04 & 1.32 & 3.45 \\
\hline
\end{tabular}

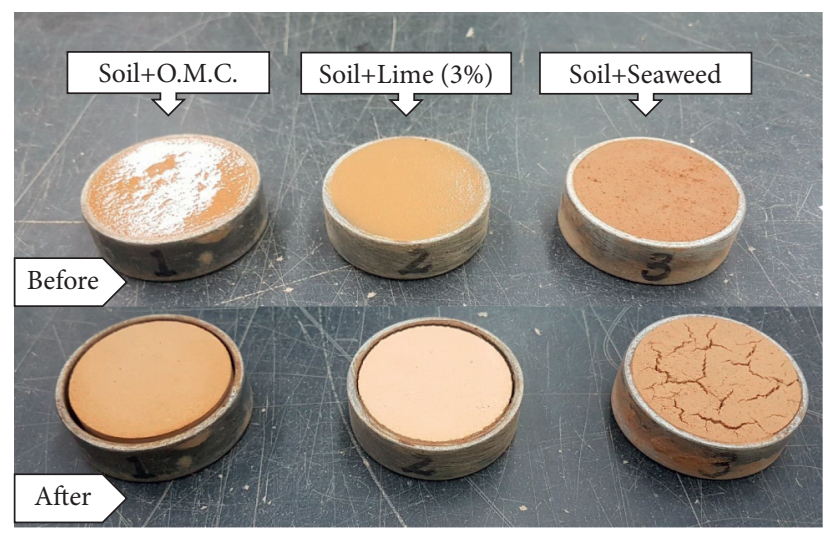

FIGURE 4: Shrinkage limit using water content.

all samples. The average water content change of the three types of samples as measured on days 3,7 , and 28 , respectively, is as follows: $2.65 \%, 1.79 \%$, and $1.60 \%$ for SO; $4.37 \%, 2.82 \%$, and $2.52 \%$ for SL; and $7.39 \%, 1.70 \%$, and $1.12 \%$ for SS. The water content changes increased in the following order: SO $>$ SL $>$ SS. Further, the water content reduction ratio of the three samples showed large differences on day 3 but no significant differences after day 7 .

For each condition, the water content ratio of change shows the most decreased after 3 days of curing time. The water content was decreased in SO by $10.7 \%$, SL by $8.98 \%$, and SS by $5.96 \%$ compared to the initial water content. Reduction in the water content was very similar to the SO and SL conditions. But SS condition seems to be low reduced water content, soil surface and void filled with gel.

\subsection{Curing-Time-Dependent Compressive Strength}

3.3.1. Compressive Strength of SO Samples. Table 4 presents an overview of the compressive strength test results of the SO samples. The average compressive strength significantly increased from the baseline value of $6.75 \mathrm{kPa}$ to $285.86 \mathrm{kPa}$ on day 3 but then increased only slightly to $321.04 \mathrm{kPa}$ on day 7 and $362.00 \mathrm{kPa}$ on day 28 . No significant changes occurred in the compressive strength after 7 days of curing in the samples prepared with the OMC.
After making specimens, the water content was greatly reduced curing time 3 days, but compressive strength has increased 3.72 times. After curing time of 3 days, compressive strength was increased by 1.12 times in curing time from 3 to 7 days and 1.27 times in curing time from 7 to 28 days, even though the compressive strength of cement was stronger at lower degrees of saturation and weaker at higher degrees of saturation for the concrete specimens [26]. The higher the degree of saturation is, the higher the water content, the consistency, the change of the consistency, and the change of the compressive strength are. The results of compressive strength according to the change of water content show a decrease in the compressive strength with higher water content [27]. The results of this study are consistent with those of Park [27] research study.

3.3.2. Compressive Strength of SL Samples. Table 5 provides an overview of the compressive strength test results of SL samples. The average compressive strength increased from the baseline value of $123.13 \mathrm{kPa}$ to $318.68 \mathrm{kPa}$ on day 3 , $404.30 \mathrm{kPa}$ on day 7 , and $411.26 \mathrm{kPa}$ on day 28 . The failure pattern observed in the samples was the increase in compressive strength over time by the load transmitted downward. After remolding the specimen, it solidified rapidly during the initial 3 days when the change in water content decreased the most as in the SO condition, and the compressive strength increased by 2.59 times at 3 days of curing. 


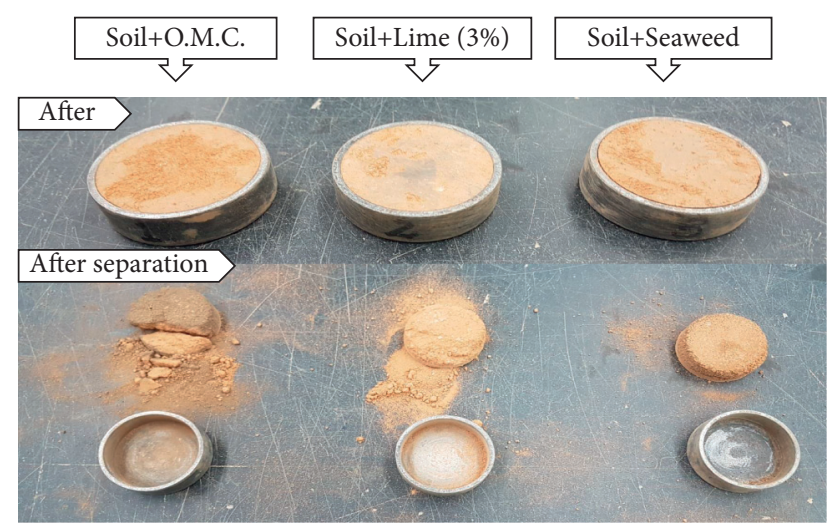

FIgURE 5: Shrinkage limit using OMC.

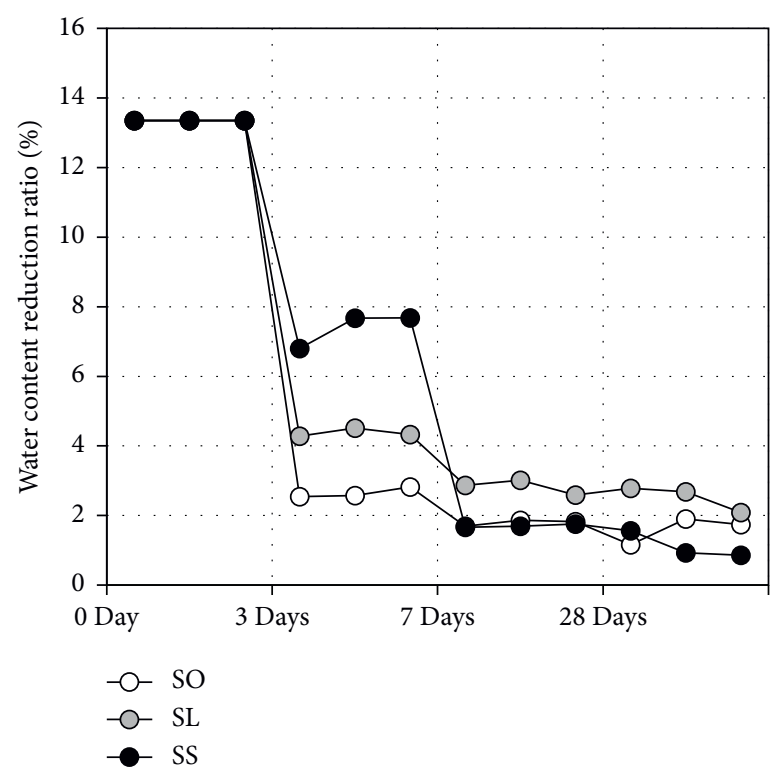

FIgURE 6: Water content change of SO, SL, and SS samples with curing time.

After that, it increased by 1.27 times from the curing time of 3 to 7 days and 1.02 times from 7 to 28 days. This change was believed to be due to the relatively small amount of water content change for each curing time of the SO condition.

3.3.3. Compressive Strength of SS Samples. Table 6 shows an overview of the compressive strength test results of SS samples. The average compressive strength increased from the baseline value of $67.05 \mathrm{kPa}$ to $169.59 \mathrm{kPa}$ on day 3 , $803.69 \mathrm{kPa}$ on day 7 , and $1090.14 \mathrm{kPa}$ on day 28. In other words, the compressive strength increased rapidly over time, with an increase to more than $100 \mathrm{kPa}$ on day $3,700 \mathrm{kPa}$ on day 7 , and $1,000 \mathrm{kPa}$ on day 28 .

Lee at al. [25] observed the microstructures of soil mixtures with organic materials and reported on the presence of a semiopaque film in Dobak-glue, either covering the particle surface or forming a gel in void. Figure 7 shows microstructure of specimens in the study of Lee at al. [25]. Moon et al. [18] noted that organic materials such as Dobak-glue mixed with soil filled up fine-grained soil particles, thereby reducing pores and yielding densely compacted particle morphologies that enhanced the compressive strength. In the results of our study as well, the SS samples showed a higher compressive strength increase rate throughout the curing time owing to the stronger binding force arising from their dense aggregation compared with those of other samples. Furthermore, the cracks that appeared in the shrinkage limit test were not observed in the samples dried under ambient conditions. After remolding the specimen, it solidified rapidly during the initial 3 days when the change in water content decreased the most as in the SO condition, and the compressive strength increased by 2.59 times at 3 days of time. After that, it increased by 1.27 times from the curing time of 3 to 7 days and 1.02 times from 7 to 28 days. Dobak-glue shows better durability than lime in the deterioration environments. Also, adhesion components make soil particle to the high-density condition and the coating on the soil surface. Even more, she study that it was show biggest durability after the weathering, because of the water resistance to the slow up the process of time [12]. This change was believed to be due to the relatively small amount of water content change for each curing time of the SO condition. 
TABLE 4: Compressive strength of SO samples with curing time $(\mathrm{kPa})$.

\begin{tabular}{lcccc}
\hline Sample & 0 days & 3 days & 7 days & 28 days \\
\hline SO_01 & 77.30 & 295.42 & 326.41 & 370.80 \\
SO_02 & 77.60 & 273.61 & 315.11 & 352.87 \\
SO_03 & 75.35 & 288.55 & 321.61 & 362.31 \\
Ave. & 76.75 & 285.86 & 321.04 & 362.00 \\
\hline
\end{tabular}

TABLE 5: Compressive strength of SL samples with curing time ( $\mathrm{kPa})$.

\begin{tabular}{lllll}
\hline Sample & 0 days & 3 days & 7 days & 28 days \\
\hline SL_01 & 121.51 & 332.06 & 416.00 & 421.82 \\
SL_02 & 122.53 & 315.15 & 382.63 & 402.40 \\
SL_03 & 125.36 & 308.84 & 414.26 & 409.56 \\
Ave. & 123.13 & 318.68 & 404.30 & 411.26 \\
\hline
\end{tabular}

TABLE 6: Compressive strength of SS samples with curing time (kPa).

\begin{tabular}{lcccc}
\hline Sample & 0 days & 3 days & 7 days & 28 days \\
\hline SS_01 & 66.36 & 180.77 & 795.98 & 1182.80 \\
SS_02 & 65.93 & 164.25 & 815.60 & 1013.91 \\
SS_03 & 65.85 & 163.75 & 799.50 & 1073.71 \\
Ave. & 67.05 & 169.59 & 803.69 & 1090.14 \\
\hline
\end{tabular}

3.4. Comparison of Compressive Strength with Curing Time. The changing trends of the strength characteristics can be traced more accurately by comparing the compressive strengths with the mixing conditions and curing time. Compressive strength by condition was summarized according to time and compared as shown in Figure 8. The results of the compressive strength test revealed that the SL sample has the highest baseline strength, with SO and SS samples showing similar compressive strength values. On day 3, SO and SL samples showed similar compressive strength that was $150 \mathrm{kPa}$ lower than that of the SS sample. On day 7, whereas the SO and SL samples showed increases of $40 \mathrm{kPa}$ and $80 \mathrm{kPa}$, respectively, the SS samples showed a significant increase of over $600 \mathrm{kPa}$. On day 28, whereas SO showed a further increase of $40 \mathrm{kPa}$ and SL showed no significant changes, the SS samples again showed a steep increase of over $200 \mathrm{kPa}$.

SL outperformed SO and SS in terms of baseline strength owing to the bonding force between the soil and the slaked lime. From day 7 to day 28, no significant changes were observed in SO and SL. In contrast, although the baseline and day 3 strength levels of SS were low, a considerable increase was observed after day 7 .

These results for SS are consistent with those reported by Lee et al. [22], which showed that the Dobak extract increased the sample strength via the formation of thin films on soil particles that increased the cohesive strength between the particles and filled up pores. Notably, the soil mixed with Dobak-glue shows good long-term strength.

In earth construction by rammed earth, a technique that uses little water, the clay component is prone to postconstruction cracking and thus requires supplementary work [28]. When building a soil wall in earth construction, the plaster is widely treated using SL dough, bitumen, or linseed oil to minimize crack formation and ensure stable strength [29]. In this context, organic materials such as Dobak-glue mixed soil are considered excellent resources ensuring stable and long-term compressive strength.

3.5. Curing-Time-Dependent Water Content Reduction and Strength Increase. Table 7 shows the change in water content and compressive strength for each condition, according to the curing time, and the correlation is shown in Figure 9. In the exponential correlation for each condition, the compressive strength tends to increase as the water content decreases.

The values indicated by the circular dotted line in Figure 9 are compressive strengths of 3 days of initial curing time, and it can be seen that the values differ greatly for each condition. It is believed that the changes in the water content ratio during the initial three days of curing time differ from each other, and the change in the water content ratio affects the compressive strength. After 3 days of curing time, in SO and SL conditions, the change in water content was very small, and the change in compressive strength was also small. However, in the case of the SS condition, the change in compressive strength at the age of 3 days is small, but it can be seen that it shows a very large increase from the curing time of 7 days.

In Figure 9, the residual water content for each condition at the minimum radius of curvature inflection point of each graph is $3.3 \%$ for SO, $4.2 \%$ for SL, and $2.0 \%$ for SS. In the graph, the inflection point for each condition is the time at which the reaction of materials to develop compressive strength begins. After the water content at the inflection point, the compressive strength shows the greatest change. 


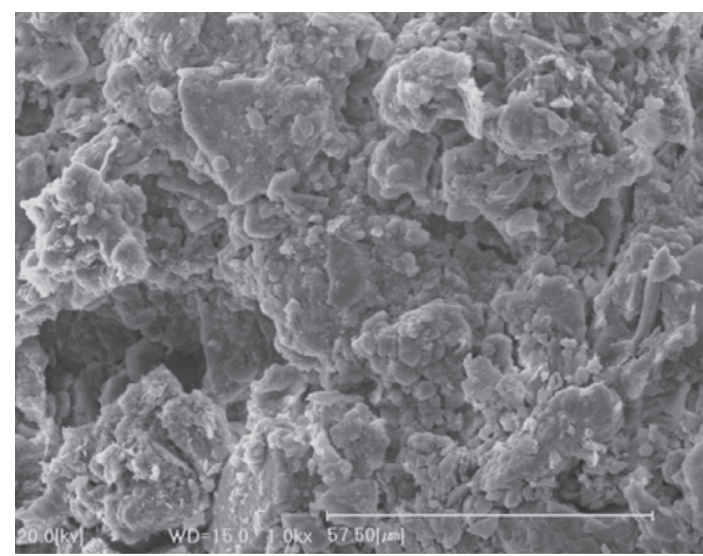

(a)

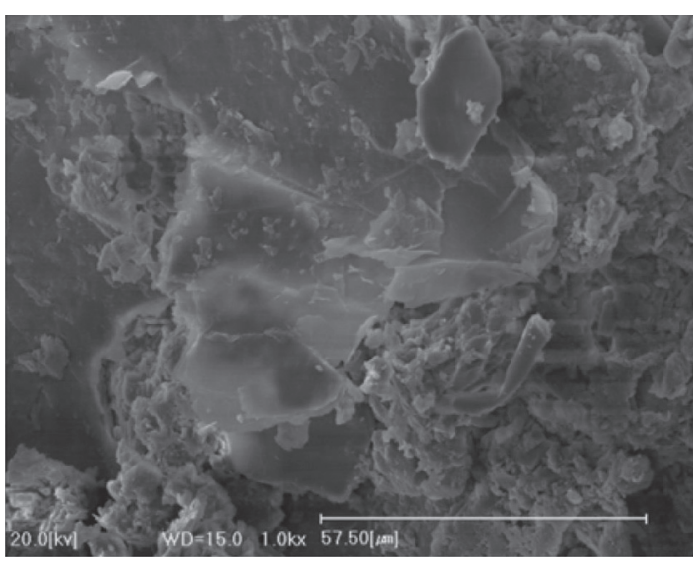

(b)

Figure 7: Microstructure of specimen [25].

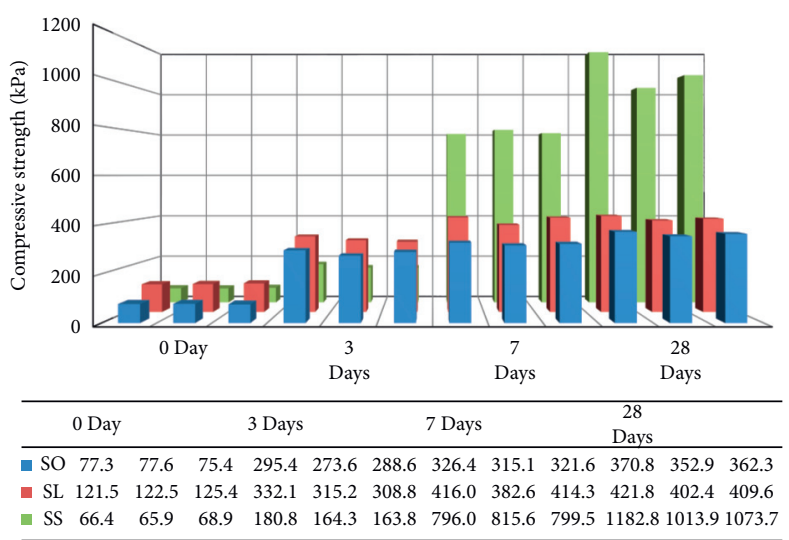

FIGURE 8: Change in compressive strength with curing time.

TABLE 7: Change of compressive strength and water content with increasing curing time.

\begin{tabular}{|c|c|c|c|c|c|c|c|c|c|}
\hline \multirow{2}{*}{ Curing time (days) } & \multicolumn{3}{|c|}{$\mathrm{SO}$} & \multicolumn{3}{|c|}{ SL } & \multicolumn{3}{|c|}{ SS } \\
\hline & 3 & 7 & 28 & 3 & 7 & 28 & 3 & 7 & 28 \\
\hline Compressive strength $(\mathrm{kPa})$ & 285.9 & 321.0 & 362.0 & 318.7 & 404.3 & 411.3 & 169.6 & 803.7 & 1090.1 \\
\hline Residual water content (\%) & 2.65 & 1.79 & 1.60 & 4.37 & 2.82 & 2.52 & 7.39 & 1.70 & 1.12 \\
\hline
\end{tabular}

The water content of the inflection point is related to the material mixed with the soil, and the mixed material acts as a cause of the difference in the bonding force of the soil, which is judged to show the difference between the curing time and the compressive strength.

Hwang et al. [30] studied the strength change of solidifying agents with different solidification principles and reported that the water content influenced the strength development and showed a correlation regardless of curing conditions. In this study, it was also found that the strength tends to increase nonlinearly with the change of the sum ratio.

Although the water content change may proceed further for each condition, it is considered that the water content change and the compressive strength change in the future will not change significantly if the humidity and environment in the atmosphere are considered. However, in the case of the SS condition, since the compressive strength is expressed over a long period of time, it was found that further research is needed from a longer-term perspective than in the case of precise evaluation of the relationship between the concentration of Dobak-glue and the mixing ratio. In addition, from the correlation between the water content change and the compressive strength, it is considered that the correlation can be applied to the compressive strength estimation for the water content change when soil and water, lime, and Dobak-glue are mixed.

A correlation between compressive strength and residual water content was also observed in the three types of soil mixture samples, as shown in Figure 9. In the case of 


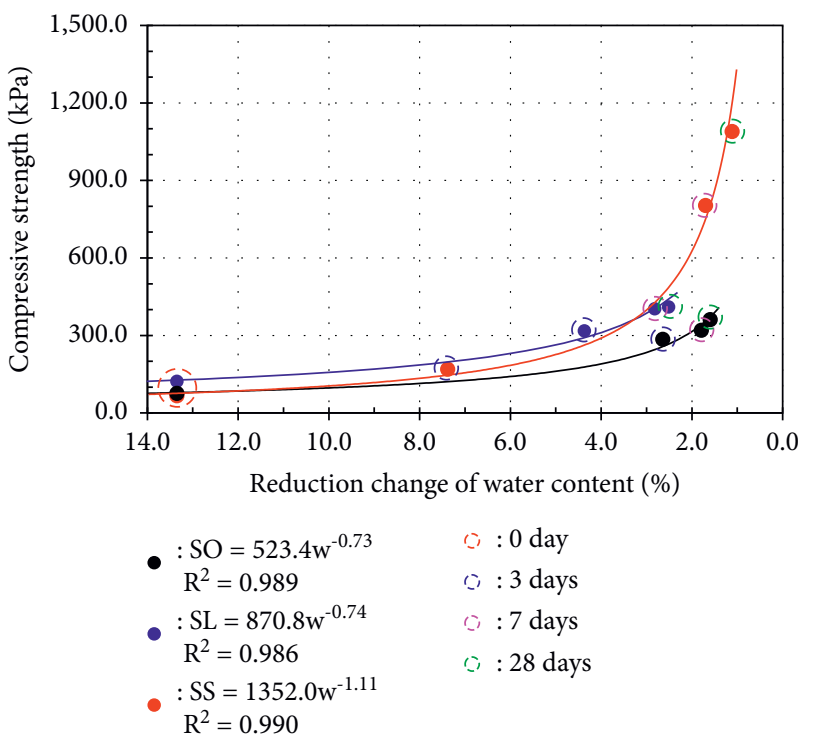

FIGURE 9: Compressive strength increase and water content reduction with curing time.

mixtures SO, SL, and SS, the relationship between the compressive strength and the residual water content in a good correlation with an $R_{2}$ value of more than 0.98 was obtained. From the graph, it can also be inferred that the Dobak-glue led to an increase in the interlocking effect between particles in compressive strength and residual water content levels.

\section{Conclusions}

This study investigated the variations in compressive strength and water content according to the curing time for Dobak-glue/soil mixtures to determine their applicability as sustainable construction materials. The results of this study can be summarized as follows:

As a result of the shrinkage limit test, it was found that the shrinkage after oven drying was smaller under the optimum water content than under the water content at the liquid limit. However, in the case of the optimum water content, the adhesion between soil particles was found to be somewhat weak under SO and SL conditions. In the SS condition, cracks occurred after drying in the liquid limit water content, but no cracks occurred under the optimum water content, and the adhesion between soil particles was also very good.

The water content by curing time was decreasing for each condition, and the decrease in water content showed small changes in SO, SL, and SS in order. Changes in water content after 7 days of curing time showed no significant difference in all conditions.

The compressive strength by curing time increased the most during the first 3 days. After that, it was found that the increase in compressive strength decreased with the passage of time to 7 and 28 days. However, it was found that under the condition of mixing Dobak-glue, the compressive strength increased very significantly from day 7 , showing a much higher value than other conditions.
Dobak-glue was found to be coated on the surface of particles when mixed with soil or increased bonding strength in the form of a gel between voids, as shown in the research results of previous researchers.

Therefore, Dobak-glue is an eco-friendly material and exhibits very excellent compressive strength when combined with soil in terms of functionality, so it is considered to be sufficient to be used as a useful material in various fields using soil.

\section{Data Availability}

The data used to support the findings of this study are included within the article.

\section{Conflicts of Interest}

The authors have no conflicts of interst to declare.

\section{Authors' Contributions}

Both authors have participated in conception and design and analysis and interpretation of data; drafting the article and revising it critically for important intellectual content; and approval of the final version.

\section{References}

[1] S. Y. Song and B. K. Koo, "The state of the art and architectural environmental property evaluation of earth construction material," KSES Journal, vol. 26, pp. 83-91, 2006.

[2] H. Y. Choi, "Environmental earth construction materials and method," Review of Architecture and Building Science, vol. 51, pp. 96-99, 2007, in Korean.

[3] M. C. J. Delgado and I. C. Guerrero, "Earth building in Spain," Construction and Building Materials, vol. 20, no. 9, pp. 679-690, 2006. 
[4] E. Quagliarini, A. Stazi, E. Pasqualini, and E. Fratalocchi, "Cob Construction in Italy: some lessons from the past," Sustainability, vol. 2, no. 10, pp. 3291-3308, 2010.

[5] T.-H. Kim and S.-W. Kim, "A study on the vernacular characteristics of contemporary earth architecture," Journal of the Korean Institute of Rural Architecture, vol. 18, no. 2, pp. 1-9, 2016, in Korean.

[6] F. Pacheco-Torgal and S. Jalali, "Earth construction: lessons from the past for future eco-efficient construction," Construction and Building Materials, vol. 29, pp. 512-519, 2012.

[7] R. Dobbs, "Prime numbers: megacities, foreign policy," 2010, http://www.foreignpolicy.com/articles/2010/08/16/prime_ numbers_megacities.

[8] J. K. Lee, J. H. kim, D. Y. Han, and W. G. Hyung, "Properties of early strength of Hwan-To mortar according to the type of inorganic binder," AIK Journal, vol. 8, pp. 475-476, 2012, in Korean.

[9] J. M. Cha, "Development of the sustainable building materials and soil," AIK Journal, vol. 12, pp. 49-53, 2003, in Korean.

[10] K. H. Yang, H. J. Hwang, S. Y. Kim, and J. G. Song, "The behavior of shrinkage strain and compressive strength of the cementless mortar using hwangto binder according to mixing conditions," Journal of The Architectural Institute Of KOREA Structure \& Construction, vol. 22, pp. 87-94, 2006, in Korean.

[11] S. H. Kim, K. S. Han, and H. S. Lee, "A study on the application of Dobak-glue for fixation painting layer of earthen mural," J. Conserv. Sci, vol. 33, pp. 533-564, 2017, in Korean.

[12] S. K. Kim and H. Y. Jeong, "Study on the filling material for the painting wall layer of the temple wall painting using a natural adhesive," Conservation Science Research, vol. 29, pp. 256-279, 2008, in Korean.

[13] National Science Museum of Korea, Traditional Science and Technology Research (IV), National Science Museum, Daejeon, South Korea, pp. 127-128, 1996 (in Korean).

[14] H. Z. Hwang and N. Y. Kang, "Preliminary study on traditional earth construction technique use of lime," The KIEAE Journa, vol. 10, pp. 3-8, 2010, in Korean.

[15] G. H. Lee, Engineering Properties and Applicability of Soil Mixed Pavement with Natural Soil Stabilizer, Inchon National University, South Korea, 2012pp. 20-69, Ph. D dissertation in Korean.

[16] E. M. Holmes, "New marine algae from Japan," Journal of the Linnean Society of London: Botany, vol. 31, no. 215, pp. 248-260, 1896.

[17] Y. Yamada, "On the Grateloupia elliptica Holmes and a group of red algae closely related to it. Manuscript of lecture at 17th Annual Meeting of Bot," Soc. Japan, 1952.

[18] H. Y. Moon, K. M. Lee, and Y. J. Chung, "A study on the manufacturing properties of soil mural's finishing layer with different types and concentration of natural adhesives," Journal of Conservation Science, vol. 34, no. 3, pp. 143-155, 2018, in Korean.

[19] Y.-M. Cho, "A study on changes of traditional wall technique," Journal of architectural history, vol. 23, no. 4, pp. 47-56, 2014, in Korean.

[20] Transportation Research Board (Trb), Lime StabilizationReactions, Properties, Design, and Construction, Vol. 5, State-of-the-art Rep, TRB, , Washington, DC, 1987.

[21] C. G. Han, M. C. Han, H. W. Kim, and D. H. Baek, "Influence of limestone coarse aggregate on properties of the concrete," AIK Journal, vol. 24, pp. 85-92, 2008, in Korean.

[22] J. K. Lee, H. S. Choi, S. K. Yoon, and W. J. Kim, "Effect of extraction temperature on some quality of sea tangle extract," KFN Journal, vol. 22, pp. 771-776, 1994, in Korean.
[23] S. J. Jung, Crack Characteristics of Compacted Soils, Master's Thesis, Korea Maritime University, Busan, Korea, 2007.

[24] Ks F 2305, Test Method for Liquid Parameters of Soils, Korean Standards Association, Seoul, South Korea, 2000.

[25] K. M. Lee, H. S. Lee, and K. S. Han, "Study on application of filling material for reinforcement of soil murals in Buddhist temple," Journal of the Korean Conservation Science for Cultural Properties, vol. 29, no. 4, pp. 395-406, 2013, in Korean.

[26] C. Xudong, "Effect of moisture content on compressive and split tensile strength of concrete," Indian Journal of Engineering and Materials Sciences, vol. 19, pp. 427-435, 2012.

[27] S. H. Park, An Experimental Study on the Relationship between Optimum Moisture Contents at Compaction and Water Content at Maximum Unconfined Compressive Strength, Master thesis, Pusan national university, Busan, South Korea, 2019.

[28] J. K. Lee, H. C. Kim, and S. W. Lee, "A case study on the method of high-rise wall in rammed earth construction," KIEAE Journal, vol. 8, pp. 85-91, 2008, in Korean.

[29] H. C. Kim, J. K. Lee, and S. W. Lee, "A case study on the method of high-rise wall in rammed earth construction," The Regional Association of Architectural Institute of Korea, vol. 12, pp. 812-817, 2007, in Korean.

[30] S. Hwang, J. Jeoung, Y. Lee, and S. Ryu, "Characteristics of organic polymer soil pavement curing condition," Journal of the Korean Geoenvironmental Society, vol. 15, no. 12, pp. 35-42, 2014, in Korean. 